\title{
Protective effects of mirtazapine in mice lacking the Mbn/2 gene in forebrain glutamatergic neurons: relevance for myotonic dystrophy 1
}

Running title: Mirtazapine: neuroprotection in a DM1 mouse model

Carla Ramon-Duaso ${ }^{1,2}$, Jose Rodríguez-Morató2,3, Estela Selma-Soriano ${ }^{4,5,6}$, Cristina FernándezAvilés ${ }^{1}$, Rubén Artero ${ }^{4,5,6}$, Rafael de la Torre ${ }^{1,2,3}$, Óscar J. Pozo ${ }^{1}$ and Patricia Robledo ${ }^{1,2^{*}}$

${ }^{1}$ Integrative Pharmacology and Systems Neuroscience, IMIM-Hospital del Mar Medical Research Institute, Barcelona, Spain

2Department of Experimental and Health Sciences, Pompeu Fabra University (CEXS-UPF), Barcelona, Spain.

${ }^{3}$ CIBER de la Fisiopatología de la Obesidad y la Nutrición (CIBERON), Instituto de Salud Carlos III, Madrid, Spain.

${ }^{4}$ Translational Genomics Group, Incliva Health Research Institute, Valencia, Spain.

5Interdisciplinary Research Structure for Biotechnology and Biomedicine (ERI BIOTECMED), University of Valencia, Valencia, Spain.

${ }^{6}$ CIPF-INCLIVA joint unit.

${ }^{*}$ Correspondence to:

Patricia Robledo

Integrative Pharmacology and Systems Neuroscience

IMIM-Hospital del Mar Medical Research Institute.

PRBB, Calle Dr. Aiguader 88, Barcelona 08003, Spain.

Email: probledo@imim.es orcid.org/0000-0002-7941-0939 
Mirtazapine: neuroprotection in a DM1 mouse model

\begin{abstract}
Myotonic dystrophy type 1 (DM1) is a multisystemic disorder characterized by muscle weakness and wasting and by important central nervous system-related symptoms including impairments in executive functions, spatial abilities and increased anxiety and depression. The Mbn/2 gene has been implicated in several phenotypes consistent with DM1 neuropathology. In this study, we developed a tissue-specific knockout mouse model lacking the Mbn/2 gene in forebrain glutamatergic neurons to examine its specific contribution to the neurobiological perturbations related to DM1. We found that these mice exhibit long-term cognitive deficits and a depressive-like state associated with neuronal loss, increased microglia and decreased neurogenesis, specifically in the dentate gyrus (DG). Chronic treatment with the atypical antidepressant mirtazapine ( 3 and $10 \mathrm{mg} / \mathrm{kg}$ ) for 21 days rescued these behavioral alterations, reduced inflammatory microglial overexpression, and reversed neuronal loss in the DG. We also show that mirtazapine re-established $5-\mathrm{HT}_{1 \mathrm{~A}}$ and histaminergic $\mathrm{H}_{1}$ receptor gene expression in the hippocampus. Finally, metabolomics studies indicated that mirtazapine increased serotonin, noradrenaline, gamma-aminobutyric acid and adenosine production. These data suggest that loss of $M b n / 2$ gene in the glutamatergic neurons of hippocampus and cortex may underlie the most relevant DM1 neurobiological and behavioral features, and provide evidence that mirtazapine could be a novel potential candidate to alleviate these debilitating symptoms in DM1 patients.
\end{abstract}

Key-words: DM1; depression; cognitive deficits; neuronal loss; inflammation; dentate gyrus 


\section{INTRODUCTION}

Myotonic dystrophy type 1 (DM1) is a multisystemic disorder caused by an RNA gain-of-function in which pathological CTG repeats generate toxic RNAs that sequester, most prominently, the muscleblind-like (MBNL) proteins (Fardaei et al., 2002). While MBNL1 is required for skeletal and cardiac muscle development, MBNL2 is highly expressed in the central nervous system (CNS) and MBNL3 is more related to placenta and fetal stage (Goodwin et al., 2015; Miller et al., 2000). Some of the features in adult-onset DM1 include muscular symptoms, cardiac arrhythmias, insulin resistance and cerebral atrophy (Udd et al., 2012; Gourdon and Meola, 2017). Also, cognitive impairments, increased anxiety and depression have been reported, indicating a dysfunction of the frontal and temporo-parietal regions (Gallais et al., 2017; Modoni et al., 2008; Sansone et al., 2007; Winblad et al., 2016). Accordingly, imaging studies have confirmed the widespread alteration of cortical and subcortical regions among patients with DM1 (Cabada et al., 2017; Minnerop et al., 2018). Moreover, loss of dopamine (DA) and serotonin (5-HT) neurons, reduced $\mathrm{N}$-acetylaspartate and reduced glutamate (Glu) were found in brains of DM1 patients (Ono et al., 1998a, 1998b; Takado et al., 2015; Vielhaber et al., 2006). Although these data point to several alterations in the brains of DM1 patients, the exact neurobiological mechanisms involved are still unknown, and no specific treatments exist for the neuropathology associated with this disabling disease (Heatwole et al., 2012).

Only a few animal models of brain-related alterations in DM1 have been developed to investigate the neurobiological substrates of this disease (Charizanis et al., 2012; Hernández-Hernández et al., 2013; Wang et al., 2017). Moreover, studies in Drosophila flies expressing CUG repeats that reproduce key features of DM1 disease, such as mis-regulated alternative splicing of muscle genes, 
Mbnl sequestration in the CNS, and CUG-dependent CNS alterations (de Haro et al., 2006), have been useful for screening new treatment strategies (Garcia-Lopez et al., 2008). In this model, $X$ chromosome-linked targeted expression of 480 CTG repeats to the mushroom bodies (MB) originates a temperature-sensitive viability phenotype that affects only females while males serve as an internal control (Garcia-Lopez et al., 2008). One class of compounds that suppressed the DM1related neurotoxicity specifically acted on dopaminergic neurons. In accordance, we have previously reported that constitutive Mbn/2 KO mice exhibiting cognitive impairment and affective deficits associated to DM1 neuropathology were reversed by chronic treatment with the psychostimulant methylphenidate (Ramon-Duaso et al., 2019).

In searching to identify novel candidates with therapeutic potential for DM1 brain phenotypes, in this study we employed the same model already used for previous drug screening; the transgenic Drosophila model to assess up to 1200 candidate drugs in functional studies. Among the chemical suppressors of DM1 toxicity found, the atypical antidepressant mirtazapine (MRZ) was selected to further investigate its potential beneficial effects in a mouse model of DM1. The rationale behind this choice was guided from previous pre-clinical reports showing that chronic treatment with MRZ increases extracellular levels of 5-HT in the frontal cortex of rats (Kamińska et al., 2018), and enhances hippocampal glutamate in both male and female Flinders rats (Kokras et al., 2009), two neurotransmitters that are altered in DM1. In addition, clinical studies show that MRZ modulates proinflammatory markers in patients with depression (Santarelli et al., 2003), which is also a hallmark of DM1 (Stenberg et al., 2013).

Since our previous data showed that constitutive Mbn/2 KO display behavioral alterations associated with major neurobiological changes in the medial prefrontal cortex (mPFC) and the hippocampus 
(HPC) (Ramon-Duaso et al., 2019), where MBNL2 protein is prominently expressed (Charizanis et al., 2012), we tested the hypothesis that loss of MBNL2 specifically in glutamatergic neurons of the forebrain would be sufficient to provoke behavioral and neurochemical alterations associated with DM1. Thus, we developed a mouse model lacking the Mbn/2 gene in glutamatergic neurons of the neocortex and HPC (Mbn/2 ${ }^{\text {NEX-cKO}) . ~ S e c o n d l y, ~ w e ~ e v a l u a t e d ~ w h e t h e r ~ M R Z ~ c o u l d ~ b e ~ a ~ t r e a t m e n t ~}$ option for suppression of brain DM1-like phenotypes and investigated its mechanisms of action. 


\section{MATERIALS AND METHODS}

\subsection{Drosophila Transgenes}

The Drosophila mushroom body-Gal4 (MB-Gal4) line (Tettamanti et al., 1997) was obtained from Dr. J.D. Armstrong (Institute of Biomedical and Life Sciences, University of Glasgow, United Kingdom) and the $y w$ line was obtained from Bloomington Drosophila Stock Center (Indiana University). The recombinant lines yw; +; UAS-CTG480 and yw; +; UAS-CTG480 UAS-GFP are described in GarciaLopez et al. 2008. Flies were maintained at $25{ }^{\circ} \mathrm{C}$ on standard nutritive medium unless stated otherwise. X chromosome-linked targeted expression of 480 CTG repeats to the mushroom bodies (MB) originates a temperature-sensitive viability phenotype that affects only females while males serve as an internal control (Fig. 1a-c). Thus, at $29^{\circ} \mathrm{C}$ no adult females hatch from the pupa whereas at $28{ }^{\circ} \mathrm{C}$ a small percentage of females are able to emerge (Garcia-Lopez et al., 2008). We used this DM1 fly model to identify drugs that significantly modify CUG repeat-induced toxicity as candidate therapies against DM1.

\subsection{Generation of Conditional Mbn/2 Knock-out Mice (Mbn/2NEX-ckO)}

To induce a tissue-specific deletion of Mbn/2 gene in forebrain glutamatergic neurons, conditional Mbn/2f/fll mice (BL6/129) (Charizanis et al., 2012), kindly provided by Dr. M. Swanson, University of Florida, were crossed with C57BL/6 NEX-Cre mice kindly provided by Dr. Klaus-Armin Nave (Max Planck Institute of Experimental Medicine, Göttingen, Germany). These transgenic mice express a Cre recombinase under the neuronal differentiation 6 (NeuroD6 or NEX) gene promoter (Goebbels et al., 2006). Each breeding cage consisted of two homozygous female mice (genotype: Mbn/21/fi) and one hemizygous male mouse (genotype: $\mathrm{Cre}^{+/}$), which generated Mbn/2NEX-cKO and WT littermates. 
Specific details regarding the generation of the conditional Mbnl2NEX-cKO mice are shown in Fig. 1d. Mice were genotyped using a PCR-based strategy to detect the presence of the LoxP flanked allele and the integration of the Cre transgene. The genotyping primers are shown in Table1.

Animal breeding and experimental procedures adhered to the standard European Directive on the protection of animals used for scientific purposes (Directive 2010/63/EU as amended by Regulation (EU) 2019/1010), and approved by the local ethical committee (CEEA) of the Barcelona Biomedical Research Park (PRBB). All experiments were carried out at the PRBB animal facility (Barcelona, Spain) that has full accreditation from the Association for Assessment and Accreditation of Laboratory Animal Care (AAALAC). All mice were grouped-housed and maintained in a temperature $\left(21 \pm 1^{\circ} \mathrm{C}\right)$ and humidity $(50 \pm 10 \%)$ controlled environment in a room with a $12 \mathrm{~h}$ light/dark cycle (lights on at 8 am and off at $8 \mathrm{pm}$ ) with food and water available ad libitum. All the behavioral experiments were performed during the light phase of the light/dark cycle by a trained observer that was blind to experimental conditions.

\subsection{Drugs and treatments}

Drosophila in vivo drug screening was performed as follows: two yw;+ ; UAS-CTG480 females were crossed with one MB-Gal4 male and placed in vials containing nutritive media supplemented with the

compounds from the Prestwick Chemical Library (PCL; 1200 compounds) (http://www.prestwickchemical.com/libraries-screening-lib-pcl.html) at $1 \mu \mathrm{M}$ final concentration. The crosses were cultured for two days at $25^{\circ} \mathrm{C}$ in 96 -well trays, where the first column contained vials of the control crosses (two $y w$ females and one MB-Gal4 male) and the twelfth column was for crossings of two yw; +; UAS-CTG480 females and one MB-Gal4 male treated with vehicle (DMSO). 
Offspring were shifted to 28 or $29^{\circ} \mathrm{C}$ till hatching and the number and sex of F1 adult progeny was scored. Compounds were tested per triplicate and those showing the capacity to rescue any female viability at $29^{\circ} \mathrm{C}$ were considered primary hits. Males were used as internal controls to discard toxic drugs.

MRZ (Alomone Labs) of a purity of $99.5 \%$ was dissolved in a vehicle solution ( $5 \%$ DMSO, $5 \%$ Tween 80 and $90 \%$ saline) and administered intraperitoneally (i.p.) in a volume of $0.1 \mathrm{ml} / 10 \mathrm{~g}$ of body weight. Drug administration was performed by a trained experimenter, and care was taken to alternate the animals' flank during chronic i.p. administrations. To determine the optimal doses of MRZ to be used for chronic administration, we first carried out a dose-response curve in locomotor studies (Fig. 1e). Male WT littermates ( $n=7$ per group) were treated once daily during 5 consecutive days with vehicle (VEH) or 1, 3, 10 and $30 \mathrm{mg} / \mathrm{kg}$ of MRZ, and locomotor activity was evaluated immediately after the last injection during $1 \mathrm{~h}$. Only the highest dose of MRZ, $30 \mathrm{mg} / \mathrm{kg}$, significantly reduced the locomotor activity in comparison with VEH administration. Thus, in the following experiments WT and Mbn/2NEX-ckO were treated once daily for 21 days with VEH or MRZ at the doses of 3 and $10 \mathrm{mg} / \mathrm{kg}$, which do not induced sedative effects, and have been found effective on depression-like and anxiety-like behavior in mice (Muguruza et al., 2013; Engel et al., 2013; Egashira et al., 2012; Oliveira et al., 2017). Only male mice were used in all experiments since in our previous studies with Mbn/2 constitutive KO mice, male KO mice were more profoundly affected by this mutation than female mice (Ramon-Duaso et al., 2019).

To analyze the effects of chronic treatment with MRZ on proliferation-related markers, one set of mice [WT ( $\mathrm{n}=4)$ and Mbn/2NEX-cko $(\mathrm{n}=4)$ per group] received a single i.p. injection of 5-bromo-2'- 
deoxyuridine (BrdU) at the dose of $100 \mathrm{mg} / \mathrm{kg}$ (Sigma, St.Louis, MO), one week after the last treatment. Mice were sacrificed $24 \mathrm{~h}$ later and brains were processed in immunohistochemistry studies. A DNA denaturation step in $2 \mathrm{M} \mathrm{HCl}$ for 15 min at $37^{\circ} \mathrm{C}$ was required for $\mathrm{BrdU}$ staining (Wojtowicz and Kee, 2006). Moreover, in these mice, the microtubule-associated protein doublecortin (DCX), that labels immature neurons that may have started to develop a differentiated neuronal morphology (Luján et al., 2018), was quantified. Both BrdU and DCX positive cells were quantified in the subgranular zone (SGZ) of the HPC, as previously described (Saravia et al., 2019).

\subsection{Behavioral assessment}

To determine if young adult Mbn/2NEX-cKO mice showed behavioral alterations, and whether these persisted over time, WT ( $n=10)$ and Mbn/2NEX-ckO $(n=10)$ were evaluated first at 3 months of age, and then again at 8 months of age in different behavioral paradigms. Locomotor activity was evaluated first (one day), followed the next day by the novel object recognition (NOR) test (3 days), and then the next day the forced swim test (FST) was performed (one day). Since Mbn/2NEX-ckO mice showed cognitive and affective deficits at 3 months of age, we performed our pharmacological experiments at this age. Thus, behavioral testing (locomotor activity, NOR test and FST) started one week (wash-out period) after repeated vehicle or MRZ administration [WT $(n=10)$ and Mbn/2NEX-cKO $(n=10)$ per treatment group] (see timeline of the behavioral procedures on Fig. 1f.)

\subsubsection{Locomotor activity assessment}

To evaluate locomotor responses in WT and Mbn/2NEX-ckO mice, mice were tested in individual locomotor boxes (9 $\times 20 \times 11 \mathrm{~cm}$; Imetronic, Bordeaux, France) equipped with two lines of infrared 
beams in low-lighting conditions (20 lux). Total horizontal activity and the number of rearings (standing on rear limbs) were analyzed during a 30 min-period.

\subsubsection{Novel Object Recognition}

Long-term recognition memory was assessed using the NOR test with the V-maze at 15 lux as previously described (Busquets-Garcia et al., 2013). Briefly, this test consists of 3 phases of 9 min each (habituation, familiarization and test). The first day, mice were habituated to the empty maze. The second day, mice were placed again in the maze and 2 identical objects were presented. Twenty-four hours later, one of the familiar objects was replaced with a novel object and the time exploring both objects (novel and familiar) was measured. Object exploration was defined as the orientation of the nose towards the object and touching it with the nose. A discrimination index (DI) was used as outcome of cognitive behavior. A higher DI score represents a greater recognition memory.

\subsubsection{Forced Swim Test}

Depressive-like behavior was evaluated using the FST (Porsolt et al., 1977). Briefly, mice were placed for 6 min into a transparent Plexiglas cylinder filled with water $\left(24 \pm 1^{\circ} \mathrm{C}\right)$, and the total immobility time was measured for the last 4 min of the test. Immobility was considered when the animal made no movements to escape. An increase in immobility is associated with a higher depressive-like state.

\subsection{Biochemical Analyses}

\subsubsection{Western blotting}


To validate the strategy of the tissue-specific Mbn/2NEX-cKO mouse line, we performed western blots to quantify the MBNL2 protein in WT $(n=6)$ and Mbn/2NEX-ckO $(n=6)$ mice. Cortical, hippocampal, striatal and cerebellar brain homogenates were obtained from mice sacrificed at 3 months of age. A general immunoblot analysis was followed as previously described (Abad et al., 2019). Briefly, to extract total protein, tissues were dounce-homogenized at $4^{\circ} \mathrm{C}$ in 30 volumes of RIPA buffer (Roche Diagnostics, Barcelona, Spain). Equal amounts of protein $(40 \mu \mathrm{g})$ were loaded onto a $10 \%$ acrylamide gel and transferred to Immobilion-P PVDF sheets (Millipore, Darmstadt, Germany). Membranes were blocked for $1 \mathrm{~h}$ at room temperature with $5 \%$ skimmed milk and incubated $2 \mathrm{~h}$ at room temperature with mouse anti-Mbnl2. Then, membranes were incubated with the corresponding anti-GAPDH. The detection was visualized by chemiluminescence ChemiDoc XRS methodology and protein expression levels were quantified by QuantityOne software (Bio-Rad, Madrid, Spain). The optical density of the bands was normalized to the amount of housekeeping control GAPDH and expressed as a percentage of control. The whole list of antibodies used in these experiments is shown in Table 1.

\subsubsection{Immunofluorescence studies}

To validate the strategy of the tissue-specific Mbn/2NEX-ckO mouse line, we also performed immunohistochemistry analyses in a separate group of mice [WT $(n=6)$ and Mbn/2NEX-ckO $(n=6)$ ] sacrificed at 3 months of age. Brains were removed, cut in a cryostat and processed to evaluate MBNL2 immunoreactivity in the MPFC and HPC.

To assess the expression of microglia, and the number of neurons in the MPFC and HPC, following MRZ chronic treatment, a separate set of mice [WT ( $n=4)$ and Mbnl2NEX-cKO $(n=4)$ per group] were sacrificed $48 \mathrm{~h}$ after the behavioral assessment, and the immunoreactivity of the ionized calcium 
binding adapter molecule 1 (Iba1), and the neuron specific nuclear protein (NeuN) was quantified, as described previously (Ramon-Duaso et al., 2019).

In all experiments, mice were anesthetized by an i.p. injection of a mixture of ketamine $(100 \mathrm{mg} / \mathrm{kg})$ and xylazine $(20 \mathrm{mg} / \mathrm{kg})$ and transcardially perfused with $4 \%$ paraformaldehyde. Coronal sections of $30 \mu \mathrm{m}$ containing the cingulate, prelimbic and infralimbic areas of the mPFC (from bregma +2.71 to $+1.70 \mathrm{~mm}$ ) and the CA1, CA3 and dentate gyrus (DG) of the HPC (from bregma -1.22 to $-2.46 \mathrm{~mm}$ ) were obtained using a cryostat (Leica CM3050 S). The primary and secondary antibodies used are listed in Table 1. Images were obtained using a Nikon Eclipse Ni-E microscope. Six to eight images were obtained within the defined region of interest (ROI) for each brain structure, and the immunoreactivity measures were averaged for each mouse. The different ROls remained constant in all experimental groups. All images were processed using the ImageJ software (NIH).

\subsubsection{Quantitative Real-Time PCR analysis}

The transcriptional levels of several neurotransmitter receptors were determined in the mPFC and $\mathrm{HPC}$, including $5-\mathrm{HT}_{1 \mathrm{~A}}, 5-\mathrm{HT}_{2 \mathrm{~A}}, 5-\mathrm{HT}_{2} \mathrm{C}, 5-\mathrm{HT}_{3}$, adrenergic $\mathrm{a}_{2 \mathrm{~A}}$ and histamine $\mathrm{H}_{1}$ following MRZ treatment [WT $(n=6)$ and Mbn/2NEX-ckO $(n=6)$ per group] in mice sacrificed $48 \mathrm{~h}$ after the behavioral assessment. Moreover, the gene expression of the pro-inflammatory marker interleukin 1 beta (IL-1 $\beta$ ) and the anti-inflammatory marker transforming growth factor (TGF- $\beta$ ) was quantified in the HPC. Brain homogenates were processed as previously described (Duart-Castells et al., 2019) with minor modifications. Total RNA isolation was carried out by RNeasy Mini Kit (Tissue; QIAGEN) and $300 \mathrm{ng}$ of each sample was reverse-transcribed using the High-Capacity cDNA Reverse Transcription Kit (Applied Biosystems, California, USA) according to the manufacturer's instructions. Real-time PCR

was performed using the PowerUp SYBR Green Master Mix and analyzed by QuantStudio ${ }^{\mathrm{TM}} 12 \mathrm{~K}$ 
Sequence Detection System (Applied Biosystems, California, USA). Primers used are listed in Table

1. mRNA expression was normalized to the relative expression value of $\beta$-actin, as endogenous housekeeping gene. Gene expression was determined using the comparative cycle threshold (Ct) method and the results are reported as fold change compared with the control.

\subsubsection{Metabolomics by LC-MS/MS}

For the targeted metabolomics study, we processed brain homogenates from the mPFC and HPC in two previously reported methods focused on the quantification of neurotransmitters and related compounds. One set of mice [WT $(n=6)$ and $\operatorname{Mbn} / 2^{N E X-c K O}(n=6)$ per group] was sacrificed one week after the last vehicle or MRZ administration, and polar neurotransmitters (GABA, glutamate, and adenosine) were determined as previously described (Olesti et al., 2019b). Given the short half-life of monoamines (Cransac, 1996), another set of mice [WT $(n=6)$ and Mbn/2NEX-ckO $(n=6)$ per group] was sacrificed 1 hour after the last vehicle or MRZ administration, and the production of NA and 5-HT was assessed (Olesti et al., 2019a). For analysis of polar neurotransmitters, an aliquot of $10 \mu \mathrm{L}$ of brain homogenate was transferred into a glass tube and was spiked with $50 \mu \mathrm{L}$ of the internal standard mixture. Then, $130 \mu \mathrm{L}$ of acetonitrile were added to precipitate the proteins. After centrifugation (5 min; $4000 \mathrm{rpm} ; 2650 \mathrm{~g}$ ) the supernatant was transferred to a microvial and directly injected into the liquid chromatography-tandem mass spectrometry (LC-MS/MS) system. A 1:100 dilution was required for the analysis of GABA, glutamine (Gln), glutamate (Glu) and adenosine. For the analysis of monoamines, an aliquot of $200 \mu \mathrm{L}$ of HPC or mPFC was transferred into a glass tube, was spiked with $100 \mu \mathrm{L}$ of internal standard mixture, and was dried under nitrogen gas. Then, it was reconstituted with $50 \mu \mathrm{L}$ of $\mathrm{NaHCO}_{3} 100 \mathrm{mM}$ buffer ( $\mathrm{pH}=10.5$ ) and was derivatized using $100 \mu \mathrm{L}$ of dansyl chloride solution $\left(1 \mathrm{mg} / \mathrm{mL}\right.$ in acetone; $\left.60^{\circ} \mathrm{C} ; 20 \mathrm{~min}\right)$. The solvent was then transferred to a microvial and was directly injected into the LC-MS/MS system. In both methods, the LC-MS/MS 
system consisted on an Acquity UPLC system (Waters Associates) for the chromatographic separation coupled to a triple quadrupole (Xevo TQ-S micro) mass spectrometer provided with an orthogonal Z-spray-electrospray interface (ESI) (Waters Associates, Milford, MA, USA). Analytes were determined by a Selected Reaction Monitoring (SRM) method by acquiring two transitions for each compound. Besides the response of the analytes, ratios between selected metabolites were also considered in order to evaluate not only the levels of neurotransmitters, but also their formation and degradation. As an example, the ratio 5-HT/Trp was selected as indicative of 5-HT biosynthesis whereas the ratio 5-HIAA/5-HT was considered for the evaluation of 5-HT degradation. MassLynx software V4.1 and TargetLynx XS were used for data management.

\subsection{Statistical Analysis}

In Drosophila studies, in vivo drug screening at $28{ }^{\circ} \mathrm{C}$ was analyzed using Fisher's exact test, in which it was assumed that the number of males is equal to the expected number of females in case the rescue was complete. One-way ANOVA was used to confirm the specific depletion of the Mbn/2 gene in the generation of the new tissue-specific mouse line. To analyze the progression of behavioral alterations a two-way ANOVA was used with genotype (WT and Mbn/2NEX-cKO) and age (3 and 8 months) as between-subject factors. The effects of chronic treatment with MRZ were analyzed

using two-way ANOVAs with genotype and dose as between-subject factors. Subsequent Bonferroni's Post-hoc test was used when required. All data were analyzed using SPSS and GraphPad Prism 8.0 software. Comparisons were statistically significant when the level of significance was $p<0.05$. 


\section{RESULTS}

\subsection{MRZ Rescues Pupal Viability in the Drosophila CNS-DM1 model}

In this study, we screened 1200 FDA-approved drugs from the Prestwick Chemical Library at the concentrations of 1 and $10 \mu \mathrm{M}$. Out of 1200 drugs tested, we identified 36 compounds that rescued the female Drosophila viability, indicating an anti-DM1 effect (Fig. 2a). These anti-DM1 compounds belonged to different therapeutic categories such as antibacterial (8\%), anti-inflammatory (11\%), and

others (81\%), which included antipsychotics, anticonvulsants and antidepressants. Among the antidepressants, MRZ showed potent anti-toxic effects in the $28{ }^{\circ} \mathrm{C}$ assay (Fig. 2b), significantly rescuing pupal viability at the doses of $1 \mu \mathrm{M}(p<0.01)$ and $10 \mu \mathrm{M}(\mathrm{p}<0.05)$, with respect to vehicle administration. Similarly, in the $29^{\circ} \mathrm{C}$ test (Fig. 2C), MRZ showed significant anti-DM1 effect at the doses of 0.1 and $1 \mu \mathrm{M}$. Due to the multifarious mechanism of action of MRZ, different from other antidepressants, its beneficial effects could have involved various neurotransmitter receptor targets. Therefore, we assessed the anti-DM1 activity of several compounds with different pharmacological profiles. Our results show that neither the $5-\mathrm{HT}$ reuptake inhibitor fluoxetine, the $5-\mathrm{HT}_{2 \mathrm{~A}}$ receptor antagonists (ritanserin and MDL-11939), nor the 5- $\mathrm{HT}_{3}$ receptor antagonist, granisetron showed any rescue of pupal viability (Fig. 2d).

\subsection{Mbnl2 ${ }^{\mathrm{NEX}-\mathrm{ckO}}$ mice show loss of MBNL2 in the MPFC and HPC}

In this study, we generated a tissue-specific mouse model selectively lacking the Mbn/2 gene in the forebrain glutamatergic neurons (Mbn/2 $\left.{ }^{\mathrm{NEX}-\mathrm{ckO}}\right)$ We confirmed the cell-specific loss of MBNL2 in excitatory neurons of the forebrain using western blot analysis of brain tissues (Fig. 2e). In brain lysates of Mbnl2 ${ }^{\text {NEX-cKO }}$ mice, MBNL2 protein levels were reduced by $90 \%$ in the mPFC (WT: 
$100 \pm 5.88, M b n / 2$ NEX-cKO: $\left.10.39 \pm 2.37 ; F_{(1,11)}=885.2, p<0.001\right)$ and by $80 \%$ in the HPC (WT: $100 \pm 2.26$, Mbn/2NEX-ckO: $\left.19.76 \pm 1.48 ; F_{(1,11)}=199.9, p<0.001\right)$ in comparison with WT mice. In the striatum and cerebellum, MBNL2 levels were not altered due to the low expression of NEX in these brain areas. Moreover, we quantified the immunoreactivity of MBNL2 protein by immunofluorescence staining in the mPFC and HPC of WT and Mbn/2 ${ }^{\mathrm{NEX}-\mathrm{ckO}}$. Accordingly, the analysis of MBNL2 expression in Mbn/2NEX-cKO mice showed a significant decrease of immunoreactivity in the mPFC $\left[F_{(1,11)}=99.0\right.$, $p<0.001]$ and $H P C\left[F_{(1,11)}=17.5, p<0.001\right]$ with respect to WT group (Fig. 2f).

\subsection{Mbn/2NEX-cko Mice Exhibit Impaired Long-term Recognition Memory and Depressive-Like Behavior}

We first performed a battery of behavioral tests in WT and Mbn/2NEX-cKO mice to assess motor, cognitive and affective processes at two time points: 3 and 8 months of age. Total horizontal locomotion and number of rearings in the locomotor cages were not significantly different between groups (Fig. 3a,b). For long-term recognition memory, a significant effect of genotype $\left[F_{(1,39)}=84.5\right.$, $p<0.001]$ and interaction $\left[F_{(2,39)}=4.8, p<0.05\right]$, but no significant effect of time were observed. Subsequent post-hoc analysis revealed that Mbn/2NEX-cKO mice exhibited a greater cognitive impairment than WT mice $(p<0.001)$ at both 3 and 8 months of age (Fig. 3c). For depressive-like behavior, a significant main effect of genotype $\left[F_{(1,39)}=102.8, p<0.001\right]$ was revealed, indicating that Mbn/2NEX-cKO exhibited higher immobility time compared to WT at both 3 and 8 months (Fig. $3 d$ ). These data indicate that the behavioral alterations observed due to loss of MBNL2 in glutamatergic neurons of the neocortex and HPC persist in time, lasting at least up to 8 months of age.

\subsection{Chronic Treatment with MRZ Reduces the Cognitive Deficits and Depressive-Like Phenotype in Mbn/2NEX-cKO Mice}


No statistical differences between treatment groups or genotypes were observed in total horizontal locomotion or number of rearings following chronic treatment with MRZ (Fig. 4a,b). In the NOR test, significant main effects of genotype $\left[F_{(1,59)}=33.4, p<0.001\right]$, treatment $\left[F_{(2,59)}=21.1, p<0.001\right]$ and interaction between factors were observed $\left[F_{(2,59)}=18.1, p<0.001\right]$. The post-hoc test revealed that Mbn/2NEX-cKO mice treated with vehicle displayed cognitive deficits in comparison with WT mice $(p<0.001)$, and chronic treatment with MRZ significantly reversed this impairment at both doses of MRZ tested $(p<0.001)$ (Fig. $4 c)$. In the $F S T$, significant main effects of genotype $\left[F_{(1,59)}=9.5, p<0.01\right]$, treatment $\left[F_{(2,59)}=8.8, p<0.001\right]$, and interaction between factors were found $\left[F_{(2,59)}=10.6, p<0.001\right]$. Subsequent analysis revealed a significant increase in immobility time in Mbn/2 ${ }^{\mathrm{NEX}-\mathrm{cKO}}$ mice treated with vehicle with respect to WT controls $(p<0.001)$, indicating a depressive-like state, that was attenuated at both doses of MRZ ( $p<0.001)$ (Fig. $4 d)$.

\subsection{Mbn/2NEX-cKO Mice Show Increased Neuroinflammation in the DG of the HPC and Chronic Treatment with MRZ reverses this Effect}

In the MPFC and the CA1 and CA3 fields of the HPC, the number of Iba1 positive cells was not significantly different between groups (Supplementary Fig. 1a-c). In contrast, in the DG, significant main effects of genotype $\left[F_{(1,23)}=18.6, p<0.001\right]$, treatment $\left[F_{(2,23)}=18.7, p<0.001\right]$, and interaction between factors $\left[F_{(2,23)}=5.7, p<0.01\right]$ were observed. Further analysis revealed a significant increase in the number of microglia in Mbn/2NEX-cKO mice treated with vehicle compared to WT controls $(p<0.001)$, and both doses of MRZ ( 3 and $10 \mathrm{mg} / \mathrm{kg}$ ) attenuated this effect $(p<0.001)$ (Fig. $5 a, d)$. Moreover, to classify the activation state of microglia in the HPC, we performed a gene expression

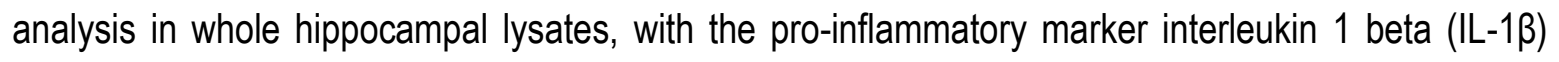
and the anti-inflammatory marker transforming growth factor (TGF- $\beta$ ). For expression of IL-1 $1 \beta$, a significant main effect of treatment $\left[F_{(2,35)}=7.1, p<0.01\right]$ and interaction between factors $\left[F_{(2,35)}=7.5\right.$, 
$p<0.01]$ were observed. Post-hoc analysis revealed an increase of transcriptional levels of IL-1 $\beta$ in Mbn/2NEX-cKO treated with vehicle with respect to WT mice $(p<0.01)$, and both doses of MRZ reversed this inflammatory process $(p<0.01)(F i g .5 b)$. However, no significant effects of treatment were observed in the gene expression of the anti-inflammatory marker TGF- $\beta$ between groups (Fig. $5 \mathrm{c}$ ).

\subsection{Mbn/2NEX-ckO Mice Exhibit Neuronal Loss in the DG of the HPC and MRZ reduces this Effect}

No statistical differences were observed between groups in the mPFC, and the CA1 and CA3 fields of the HPC (Supplementary Fig. 1d-f). In contrast, in the DG, a significant interaction between factors $\left[F_{(2,23)}=5.6, p<0.01\right]$ was found, but no significant main effects of genotype or treatment. Moreover, the post-hoc test revealed that vehicle-treated Mbn/2NEX-cKO mice showed a significant decrease in the number of NeuN positive cells with respect to WT mice $(p<0.01)$, and this effect was reversed with the dose of $10 \mathrm{mg} / \mathrm{kg}$ of MRZ (p<0.05) (Fig. 6a,b).

Given that increased microglia and neuronal loss were mainly observed in the DG, we performed studies of neurogenesis and apoptosis, two processes that could be dysregulated in Mbn/2NEX-cKO mice. In BrdU immunostaining, although a tendency for less cell proliferation in vehicle-treated Mbn/2NEX-CKO mice was observed in comparison with WT mice, a significant main effect of treatment $\left[F_{(2,23)}=76.1, p<0.01\right]$ was revealed, but with no main effect of genotype or interaction between factors, indicating that MRZ increased cell proliferation in both genotypes equally (Fig. 6c,d). For DCX expression, a significant main effect of treatment $\left[F_{(2,23)}=40.6, p<0.001\right]$, and interaction between factors $\left[F_{(2,23)}=4.6, p<0.05\right]$ was observed, with no main effect of genotype. Further analysis revealed a significant decrease of DCX integrated density in Mbn/2NEX-cKO treated with vehicle compared to WT group ( $p<0.001)$, indicating a reduction of immature cells in Mbn/2NEX-ckO mice. MRZ, 
however, significantly increased DCX in both genotypes to a similar extent $(p<0.01)$ (Fig. 6e,f). No significant differences between groups treated with vehicle were observed in caspase-3 protein (data now shown), indicating that there is no deregulation in the cell death cycle.

\subsection{MRZ Modulates the Expression of 5-HT $1 \mathrm{~A}$ and $\mathrm{H}_{1}$ Receptors in the HPC of Mbn/2 ${ }^{\mathrm{NEX}-\mathrm{cKO}}$ mice}

Changes in the transcriptional activity of $\mathrm{a}_{2}$-adrenergic, serotonergic $5-\mathrm{HT} \mathrm{T}_{1 \mathrm{~A}}, 5-\mathrm{HT}_{2 \mathrm{~A}}, 5-\mathrm{HT} \mathrm{T}_{2 \mathrm{C}}, 5-\mathrm{HT} \mathrm{T}_{3}$, and histaminergic $\mathrm{H}_{1}$ receptors in the MPFC and HPC of WT and Mbn/2 ${ }^{\text {NEX-cKO }}$ mice were assessed. In the mPFC, a main effect of genotype was revealed for $5-H T_{1 A} R$ mRNA levels $\left[F_{(2,35)}=24.8\right.$, $p<0.001]$, indicating a lower expression in Mbn/2NEX-ckO mice (Supplementary Fig. 2a). For $a_{2 A}$ receptor, a significant interaction was observed between factors $\left[F_{(2,35)}=3.0, p<0.05\right]$. Post-hoc analysis revealed decreased levels of alpha $2 \mathrm{~A}$ receptor in Mbn/2NEX-cKO mice treated with vehicle as compared with WT mice $(p<0.05)$, but no significant differences between genotypes were found following MRZ treatment (Supplementary Fig. 2b). No significant differences between groups were revealed for the $5-\mathrm{HT}_{2 \mathrm{~A}}, 5-\mathrm{HT}_{2} \mathrm{C}$, or $5-\mathrm{HT}_{3}$ receptors or for the histamine $\mathrm{H}_{1}$ receptor (Supplementary Fig. 2c-f).

In the HPC, statistical analysis showed a significant main effect of genotype for $5-\mathrm{HT}_{2 \mathrm{~A}}\left[\mathrm{~F}_{(2,35)}=5.9\right.$, $p<0.05]$ and for $5-H T_{2 C}\left[F_{(2,35)}=8.3, p<0.01\right]$ gene expression (Fig. 7a,b). For $5-H T_{1 A} R$ gene expression, a significant interaction between genotype and treatment was observed $\left[F_{(2,35)}=5.8\right.$, $p<0.01]$. Post-hoc comparisons showed that $5-\mathrm{HT}_{1 A} \mathrm{R}$ mRNA levels were significantly decreased in vehicle-treated Mbn/2NEX-cKO mice as compared to WT mice $(p<0.05)$, and MRZ reverse this effect at the dose of $10 \mathrm{mg} / \mathrm{kg}(\mathrm{p}<0.001)$ (Fig. 7c). For the transcriptional levels of histaminergic $\mathrm{H}_{1}$ receptor, a significant main effect of genotype $\left[F_{(2,35)}=5.1, p<0.05\right]$ and a significant interaction between genotype 
and treatment $\left[F_{(2,35)}=12.2, p<0.001\right]$ were found. Subsequent analysis showed a significant increase of $\mathrm{H}_{1}$ levels in Mbn/2NEX-ckO mice treated with vehicle as compared to WT group $(\mathrm{p}<0.001)$, and MRZ reverse this effect at the dose of $3 \mathrm{mg} / \mathrm{kg}(p<0.01)$ and $10 \mathrm{mg} / \mathrm{kg}(p<0.001)$ (Fig. $7 \mathrm{~d})$. For $\mathrm{a}_{2 \mathrm{~A}}$ and $5-$ $\mathrm{HT}_{3}$ receptor expression, no significant differences between groups were revealed (Fig. 7e-f).

\subsection{MRZ Modulates Monoamine, GABA and Adenosine production in the HPC of Mbn/2 ${ }^{\text {NEX-ckO }}$ mice}

To further examine possible alterations in neurotransmitter systems, we performed targeted metabolomics studies after chronic treatment (21 days) with vehicle or MRZ ( 3 and $10 \mathrm{mg} / \mathrm{kg}$ ) in brain homogenates of mPFC and HPC of WT and Mbn/2NEX-cKO mice. 5-HT production was determined by the 5-HT/Trp ratio. In the mPFC, statistical analysis revealed a significant interaction between factors $\left[F_{(2,35)}=4.2, \quad p<0.05\right]$, but no significant main effects of genotype or treatment. Post-hoc analysis showed that chronic treatment with $10 \mathrm{mg} / \mathrm{kg}$ of MRZ significantly reduced the generation of $5-\mathrm{HT}$ in WT mice compared to those treated with vehicle $(\mathrm{p}<0.001)$ (Fig. 8a). In contrast, in the HPC, a significant interaction in the ratio $5-\mathrm{HT} / \operatorname{Trp}\left[\mathrm{F}_{(2,30)}=6.4, \mathrm{p}<0.01\right]$. Subsequent analysis exhibited a significant decrease in the production of 5-HT from its precursor Trp in Mbn/2NEX-ckO mice treated with vehicle compared to WT mice $(p<0.05)$. Moreover, MRZ at $10 \mathrm{mg} / \mathrm{kg}$ significantly reduced the generation of 5-HT in WT mice in comparison with WT group treated with vehicle $(p<0.05)$ (Fig. 8f). No significant differences were observed when considering 5-HT degradation (5-HIAA/5-HT) (data not shown). NA production was assessed by the NA/Tyr ratio. In the mPFC, a significant interaction between factors $\left[F_{(2,35)}=5.4, p<0.05\right]$ was observed with a significant decrease of NA production in Mbn/2NEX-ckO mice treated with vehicle compared to WT mice $(p<0.05)$, while MRZ at $10 \mathrm{mg} / \mathrm{kg}$ significantly reduced the generation of NA in WT mice compared to WT group $(p<0.05)$ (Fig. 8b). In the HPC, a significant main effect of genotype $\left[F_{(1,35)}=17.9, p<0.001\right]$ and interaction between factors 
$\left[F_{(2,35)}=5.9, p<0.01\right]$ was revealed. Post-hoc analysis showed an increase in NA production in Mbn/2NEX-ckO mice treated with MRZ at $10 \mathrm{mg} / \mathrm{kg}$ in comparison with WT group $(\mathrm{p}<0.001)$, while this dose of MRZ reduced the production of NA in the WT group in comparison with WT mice treated with vehicle $(p<0.05)$ (Fig. 8g). No significant differences were observed when considering NA degradation (NMN/NA) (data not shown).

GABA production was evaluated by the GABA/Glu ratio. In the mPFC, no significant differences between groups were found (Fig. 8c). In contrast, in the HPC, a significant interaction between factors was observed $\left[F_{(2,35)}=4.8, p<0.05\right]$. Subsequent analysis revealed a significant increase of GABA production in Mbn/2NEX-ckO mice treated with MRZ $10 \mathrm{mg} / \mathrm{kg}$ in comparison with Mbn/2NEX-cKO mice treated with vehicle $(\mathrm{p}<0.05)$ (Fig. 8h). Finally, Glu production was determined by the Glu/Gln ratio. Statistical analysis only showed a significant main effect of genotype in $\operatorname{mPFC}\left[F_{(1,35)}=5.0\right.$, $p<0.05]$ and HPC $\left[F_{(1,35)}=28.3, p<0.001\right]$, indicating that Mbn/2NEX-cKO mice had lower generation of Glu compared to WT group (Fig 8d, i).

For adenosine concentrations, a main effect of genotype $\left[F_{(1,35)}=4.4, p<0.05\right]$ in the mPFC was observed due to an increase in WT mice treated with $10 \mathrm{mg} / \mathrm{kg}$ of MRZ, with no main effect of treatment or interaction between factors (Fig. 8e). In the HPC, a significant interaction was found $\left[F_{(2,35)}=4.4, p<0.05\right]$, with no main effects of genotype or treatment. Post-hoc analysis revealed a significant reduction of adenosine levels in Mbn/2NEX-cKO mice treated with vehicle in comparison with WT group $(p<0.05)$ and the dose of $10 \mathrm{mg} / \mathrm{kg}$ of MRZ reversed this effect $(\mathrm{p}<0.05)$ (Fig. 8j). 


\section{DISCUSSION}

Our previous work demonstrated that constitutive deletion of Mbn/2 in mice resulted in cognitive impairments and depressive-like behavior, that persisted up to 5 months of age, recapitulating the neuropsychological disturbances observed in DM1 (Ramon-Duaso et al., 2019). The present findings reveal that conditional loss of the Mbn/2 gene specifically in forebrain glutamatergic neurons of the PFC and HPC provoked: (i) long-lasting DM1-related behavioral disturbances, and (ii) neuronal and glial alterations in the DG and receptor/neurotransmitter changes in the HPC. Accordingly, deregulation of neural networks between MPFC and HPC has been shown to occur in DM1 patients (Romeo et al., 2010), and is associated to alterations in cognition and affective functions (Richardson and Adams, 2018; Sampath et al., 2017). Several clinical studies have shown that most patients with depression, including DM1 patients (Nätterlund and Ahlström, 2001), report significant deficits in executive function, memory and attention (Kaser et al., 2017; Russo et al., 2015). Although both cognitive dysfunction and depression represent a major burden for patients and family, there are no medications currently approved for treating the complex CNS symptomatology seen in DM1 patients.

Our in vivo screening results in a transgenic Drosophila showed that the atypical antidepressant, MRZ was able to rescue female pupal viability, suggesting anti-CNS-related toxicity in this DM1 fly model. To explore the mechanisms of action of MRZ, we treated flies with compounds known to be targets of MRZ. The results revealed that neither the SSRI, fluoxetine nor the $5-\mathrm{HT}_{2 A} \mathrm{R}$ antagonists (ritanserin and MDL-11939), or the 5- $\mathrm{HT}_{3} \mathrm{R}$ antagonist, granisetron induced anti-toxicity effects when tested individually. These findings suggested that the effects of MRZ could be due to a combinatory action on all of these targets, or on other neurotransmitter receptors that were not tested in the assay. Therefore, we examined the effects of MRZ on the behavioral and neurochemical alterations observed in the Mbn/2NEX-ckO mouse model, selecting two low doses ( 3 and $10 \mathrm{mg} / \mathrm{kg}$ ) from our pilot 
study that did not reduce locomotor activity in WT mice, to ensure the lack of confounding sedative effects in our behavioral studies. Indeed, some clinical trials have shown that small doses of MRZ may induce excessive sedation, while other studies have not reported this effect (Anttila and Leinonen, 2001). Our data in Mbn/2NEX-cKO mice showed that MRZ reversed both cognitive impairment and depressive-like behavior without affecting locomotor activity. These findings are consistent with previous results in mice showing that MRZ attenuates depressive-like behavior (Engel et al., 2013), and increases memory retention when co-administered with risperidone in a model of psychotic-like behavior (Rogóż, 2013). In addition, clinical studies have reported that MRZ can enhance cognitive performance in depressed (Santarelli et al., 2003; Borkowska et al., 2007), and schizophrenic (Cho et al., 2011; Stenberg et al., 2013) patients.

The behavioral changes in Mbn/2NEX-ckO mice were associated with an increase in the numbers of microglia specifically in the DG of the HPC in comparison with WT mice. Moreover, the transcriptional levels of the pro-inflammatory cytokine, IL-1 $\beta$, were enhanced in the HPC of these mice, while no alterations were found in the gene expression of TGF- $\beta$, an anti-inflammatory cytokine. Interestingly, previous studies have reported a microglia enhancement in DM1 brains (Satoh et al., 2016), attributable to a high prevalence of white matter damage in this disease (Itoh et al., 2010). In addition, Mbn/2NEX-CKO mice exhibited significant neuronal loss, decreased neurogenesis, and significantly fewer proliferating and immature neurons in the DG of the HPC. These findings are consistent with the diffuse brain damage observed in DM1 patients (Itoh et al., 2010; Mizukami et al., 1999; Takado et al., 2015), and with the data showing that both depression and cognitive deficits are related to altered neurogenesis in the HPC (Cao et al., 2004; Papakostas and Culpepper, 2015). While the behavioral alterations observed in the tissue-specific Mbnl2 ${ }^{\text {NEX-cKO }}$ model are similar to those observed in constitutive Mbn/2 mice (Ramon-Duaso et al., 2019), the associated changes in neuronal 
and glial cells show several differences in both models. Hence, in the constitutive KO we observed more extended microgliosis, including the mPFC and the entire HPC, but no neuronal loss. In the conditional KO however, microgliosis was restricted to the DG of the HPC, where neuronal loss was also present. These findings imply that loss of MBNL2 constitutively induces more wide-spread brain inflammation than a tissue-specific deletion in glutamatergic neurons. Moreover, the specific effects observed in the DG indicate that this structure is particularly sensitive to the lack of MBNL2 protein, leading to the observed behavioral deficits. In accordance, studies in rats have demonstrated that the DG is required to mediate pattern separation (Kesner and Rogers, 2004), a central mechanism for novelty detection within an environment and for learning and memory (Bakker et al., 2008). In fact, it has been described that DG-lesioned rats are not able to discriminate between the familiar and novel object (Hunsaker and Kesner, 2008). Also, impaired adult neurogenesis in the DG has been related to depressive states (Jacobs et al., 2000). Overall, our data reveal that lack of MBNL2 protein in the DG (inducing neuronal loss, decreased neurogenesis, and inflammatory microglia activation) is sufficient to cause cognitive deficits and depression-like behavior.

Notably, chronic treatment with MRZ attenuated the increased numbers of microglia, the overexpression of a pro-inflammatory cytokine, the reduction in neurons in Mbn/2NEX-cKO mice, and increased neurogenesis in the DG of WT and Mbnl2NEX-cKO mice. Thus, by restoring neuronal and glial function in the DG of the HPC, MRZ may reverse the depressive-like behavior and cognitive impairment in Mbn/2NEX-cKO mice. In accordance, cellular adaptations in the HPC after repeated antidepressant administration have been shown to play an important role in their behavioral effects (Malberg et al., 2000; Santarelli et al., 2003). Moreover, chronic treatment with MRZ decreases plasma levels of pro-inflammatory markers in depressed patients (Tulner et al., 2011), and 
reestablishes the equilibrium between physiological and pathological levels of cytokines in the brain (Müller and Schwarz, 2007; Sutcigil et al., 2007).

Chronic treatment with MRZ abrogated the cellular and behavioral alterations in Mbn/2NEX-ckO mice. We cannot rule out completely that the mechanism of action underlying the beneficial effects of MRZ were due to a restoration of Mbn/2 or modulation of Mbnl1 gene expression or protein levels in the brain of conditional KO mice. However, it is more likely that the effects of MRZ impinged on the transcriptional activity of its known receptor targets (de Boer, 1996), and/or on the regulation of specific neurotransmitter levels. Interestingly, our data showed selective changes in gene expression levels of two receptors in the HPC of Mbn/2NEX-ckO mice. First, $5-\mathrm{HT}_{1 \mathrm{~A}} \mathrm{R}$ gene expression was significantly reduced, while $H_{1} R$ transcriptional levels were increased. Notably, MRZ reversed both of these alterations, which is consistent with the idea that the beneficial effects of MRZ are probably mediated by $5-\mathrm{HT}_{1 \mathrm{~A}} \mathrm{R}$ and $\mathrm{H}_{1} \mathrm{R}$, two crucial receptors related to depression-like behavior and memory deficits (Strobel et al., 2003; Wolff et al., 2004; Le François et al., 2008) and inflammatory processes (Rocha et al., 2016), respectively. Secondly, using targeted metabolomics we found that Mbnl2NEX-cKO mice treated with vehicle presented a significantly lower production of $5-\mathrm{HT}$ and adenosine in the HPC. Accordingly, loss of 5-HT neurons has been reported in DM1 patients (Ono et al., 1998a). As expected by its mechanisms of action, chronic treatment with MRZ at $10 \mathrm{mg} / \mathrm{kg}$ increased 5-HT and NA production (Anttila and Leinonen, 2001). Interestingly, we also found that this dose of MRZ increased GABA and adenosine production in the HPC of Mbn/2NEX-cKO mice. This result is in line with previous studies showing that MRZ increases GABA and reduces Glu concentrations in nucleus accumbens homogenates in a rat model of chronic mild stress (Kamal, 2013). While no evidence is currently available as to the effects of MRZ on adenosine neurotransmission, our data suggests that this compound may be increasing adenosine in the HPC to modulate neuronal and glial stability. 
Indeed, adenosine acting on $A_{1}$ receptors reduces excitatory transmission, and is neuroprotective in brain injuries (Ribeiro et al., 2002).

Overall, these data reveal that the beneficial effects of MRZ may be associated with re-establishing receptor function in known targets, such as $5-\mathrm{HT}_{1 \mathrm{~A}} \mathrm{R}$ and $\mathrm{H}_{1} \mathrm{R}$, and also by alternative mechanisms involving GABA and adenosine neurotransmission in the HPC. Finally, it is important to point out that since all our studies were carried out in male mice; care should be taken when extrapolating these findings to female mice.

In conclusion, using the Mbn/2NEX-cKO mouse model we revealed that specific loss of MBNL2 protein in the hippocampus and cortex leads to brain-related DM1 behavioral and neurochemical phenotypes. In addition, we provide evidence that MRZ could be a potential new treatment to counteract the cognitive and affective disorders observed in DM1, through a mechanism of action involving known targets, such as $5-\mathrm{HT}$ and histaminergic receptors, but also through a novel mechanism of action involving GABA and adenosine neurotransmission. 


\section{Acknowledgements}

We thank Dr. Rafael Maldonado for fruitful discussions; Dr. Maurice S. Swanson from University of Florida, College of Medicine, and Dr. Klaus Nave from the Max Planck Institute of Experimental Medicine for providing the conditional Mbn/2floxffox, and the Nex-Cre mice, respectively; Dr. J. Fernandez-Costa for know-how about Drosophila screening formats and Dr. B. Llamusí, and Arturo Lopez-Castel for stimulating discussions of the results.

\section{Author contributions}

PR, RTF, OJP, RA, JRM and CRD designed research; CRD, CFA, ESS and JRM performed the research; CRD, JRM and ESS analyzed data; CRD wrote the first draft of the paper; PR, OJP, ESS and JRM edited the paper. All authors approved the final version of the paper.

\section{Funding}

Fundació la Marató de TV3 (231/C/2014). Spanish Health National System is acknowledged for OP; contract (CPII16/00027). EU's Horizon 2020 research and innovation program under the Marie Sklodowska-Curie grant No. 712949 (TECNIOspring PLUS) and from ACCIÓ (JRM). This work was supported by grants from DIUE de la Generalitat de Catalunya 2017 SGR 138 (RTF) from the Departament d'Economia i Coneixement de la Generalitat de Catalunya (Spain).

\section{Conflict of Interest}

The authors declare no competing financial interests. 


\section{REFERENCES}

Abad, S., Ramon-Duaso, C., López-Arnau, R., Folch, J., Pubill, D., Camarasa, J., Camins, A., Escubedo, E., 2019. Effects of MDMA on neuroplasticity, amyloid burden and phospho-tau expression in APPswe/PS1dE9 mice. J. Psychopharmacol. 269881119855987. https://doi.org/10.1177/0269881119855987

Anttila, S.A., Leinonen, E. V, 2001. A review of the pharmacological and clinical profile of mirtazapine. CNS Drug Rev. 7, 249-64. https://doi.org/10.1111/j.1527-3458.2001.tb00198.x

Baharav, E., Bar, M., Taler, M., Gil-Ad, I., Karp, L., Weinberger, A., Weizman, A., 2012. Immunomodulatory effect of sertraline in a rat model of rheumatoid arthritis. Neuroimmunomodulation 19, 309-18. https://doi.org/10.1159/000339109

Bakker, A., Kirwan, C.B., Miller, M., Stark, C.E.L., 2008. Pattern separation in the human hippocampal CA3 and dentate gyrus. Science (80). https://doi.org/10.1126/science.1152882

Borkowska, A., Drozdz, W., Ziółkowska-Kochan, M., Rybakowski, J., 2007. Enhancing effect of mirtazapine on cognitive functions associated with prefrontal cortex in patients with recurrent depression. Neuropsychopharmacol. Hung. 9, 131-6.

Busquets-Garcia, A., Gomis-González, M., Guegan, T., Agustín-Pavón, C., Pastor, A., Mato, S., Pérez-Samartín, A., Matute, C., de la Torre, R., Dierssen, M., Maldonado, R., Ozaita, A., 2013. Targeting the endocannabinoid system in the treatment of fragile $X$ syndrome. Nat. Med. 19, 603-607. https://doi.org/10.1038/nm.3127

Cabada, T., Iridoy, M., Jericó, I., Lecumberri, P., Seijas, R., Gargallo, A., Gomez, M., 2017. Brain Involvement in Myotonic Dystrophy Type 1: A Morphometric and Diffusion Tensor Imaging Study with Neuropsychological Correlation. Arch. Clin. Neuropsychol. 32, 401-412. https://doi.org/10.1093/arclin/acx008

Cao, L., Jiao, X., Zuzga, D.S., Liu, Y., Fong, D.M., Young, D., During, M.J., 2004. VEGF links hippocampal activity with neurogenesis, learning and memory. Nat. Genet. 36, 827-35. https://doi.org/10.1038/ng1395

Charizanis, K., Lee, K.-Y., Batra, R., Goodwin, M., Zhang, C., Yuan, Y., Shiue, L., Cline, M., Scotti, M.M., Xia, G., Kumar, A., Ashizawa, T., Clark, H.B., Kimura, T., Takahashi, M.P., Fujimura, H., Jinnai, K., Yoshikawa, H., Gomes-Pereira, M., Gourdon, G., Sakai, N., Nishino, S., Foster, T.C., Ares, M., Darnell, R.B., Swanson, M.S., 2012. Muscleblind-like 2-mediated alternative splicing in the developing brain and dysregulation in myotonic dystrophy. Neuron 75, 437-50. https://doi.org/10.1016/j.neuron.2012.05.029 
Cho, S.J., Yook, K., Kim, B., Choi, T.K., Lee, K.S., Kim, Y.W., Lee, J.E., Suh, S., Yook, K.H., Lee, S.$H_{.}$, 2011. Mirtazapine augmentation enhances cognitive and reduces negative symptoms in schizophrenia patients treated with risperidone: a randomized controlled trial. Prog. Neuropsychopharmacol. Biol. $\quad$ Psychiatry 208-11. https://doi.org/10.1016/j.pnpbp.2010.11.006

Cransac, H., 1996. Monoamines (norepinephrine, dopamine, serotonin) in the rat medial vestibular nucleus: Endogenous levels and turnover. J. Neural Transm. https://doi.org/10.1007/BF01276416

de Boer, T., 1996. The pharmacologic profile of mirtazapine. J. Clin. Psychiatry 57 Suppl 4, 19-25.

de Haro, M., Al-Ramahi, I., De Gouyon, B., Ukani, L., Rosa, A., Faustino, N.A., Ashizawa, T., Cooper, T.A., Botas, J., 2006. MBNL1 and CUGBP1 modify expanded CUG-induced toxicity in a Drosophila model of myotonic dystrophy type 1. Hum. Mol. Genet. 15, 2138-45. https://doi.org/10.1093/hmg/ddl137

Duart-Castells, L., López-Arnau, R., Vizcaíno, S., Camarasa, J., Pubill, D., Escubedo, E., 2019. 7,8Dihydroxyflavone blocks the development of behavioral sensitization to MDPV, but not to cocaine: Differential role of the BDNF-TrkB pathway. Biochem. Pharmacol. 163, 84-93. https://doi.org/10.1016/j.bcp.2019.02.004

Egashira, N., Shirakawa, A., Abe, M., Niki, T., Mishima, K., Iwasaki, K., Oishi, R., Fujiwara, M., 2012. $\mathrm{N}$-acetyl-L-cysteine inhibits marble-burying behavior in mice. J. Pharmacol. Sci. https://doi.org/10.1254/jphs.11228SC

Engel, D., Zomkowski, A.D.E., Lieberknecht, V., Rodrigues, A.L., Gabilan, N.H., 2013. Chronic administration of duloxetine and mirtazapine downregulates proapoptotic proteins and upregulates neurotrophin gene expression in the hippocampus and cerebral cortex of mice. J. Psychiatr. Res. 47, 802-808. https://doi.org/10.1016/j.jpsychires.2013.02.013

Fardaei, M., Rogers, M.T., Thorpe, H.M., Larkin, K., Hamshere, M.G., Harper, P.S., Brook, J.D., 2002. Three proteins, MBNL, MBLL and MBXL, co-localize in vivo with nuclear foci of expanded-repeat transcripts in DM1 and DM2 cells. Hum. Mol. Genet. 11, 805-14. https://doi.org/10.1093/hmg/11.7.805

Gallais, B., Gagnon, C., Mathieu, J., Richer, L., 2017. Cognitive decline over time in adults with myotonic dystrophy type 1: A 9-year longitudinal study. Neuromuscul. Disord. 27, 61-72. https://doi.org/10.1016/j.nmd.2016.10.003 
Garcia-Lopez, A., Monferrer, L., Garcia-Alcover, I., Vicente-Crespo, M., Alvarez-Abril, M.C., Artero, R.D., 2008. Genetic and chemical modifiers of a CUG toxicity model in Drosophila. PLoS One 3, e1595. https://doi.org/10.1371/journal.pone.0001595

Goebbels, S., Bormuth, I., Bode, U., Hermanson, O., Schwab, M.H., Nave, K.-A., 2006. Genetic targeting of principal neurons in neocortex and hippocampus of NEX-Cre mice. Genesis 44, 611-21. https://doi.org/10.1002/dvg.20256

Goodwin, M., Mohan, A., Batra, R., Lee, K.-Y., Charizanis, K., Fernández Gómez, F.J., Eddarkaoui, S., Sergeant, N., Buée, L., Kimura, T., Clark, H.B., Dalton, J., Takamura, K., WeynVanhentenryck, S.M., Zhang, C., Reid, T., Ranum, L.P.W., Day, J.W., Swanson, M.S., 2015. MBNL Sequestration by Toxic RNAs and RNA Misprocessing in the Myotonic Dystrophy Brain. Cell Rep. 12, 1159-68. https://doi.org/10.1016/j.celrep.2015.07.029

Gourdon, G., Meola, G., 2017. Myotonic Dystrophies: State of the Art of New Therapeutic Developments for the CNS. Front. Cell. Neurosci. 11, 101. https://doi.org/10.3389/fncel.2017.00101

Heatwole, C., Bode, R., Johnson, N., Quinn, C., Martens, W., McDermott, M.P., Rothrock, N., Thornton, C., Vickrey, B., Victorson, D., Moxley, R., 2012. Patient-reported impact of symptoms in myotonic dystrophy type 1 (PRISM-1). Neurology 79, 348-57. https://doi.org/10.1212/WNL.0b013e318260cbe6

Hernández-Hernández, O., Guiraud-Dogan, C., Sicot, G., Huguet, A., Luilier, S., Steidl, E., Saenger, S., Marciniak, E., Obriot, H., Chevarin, C., Nicole, A., Revillod, L., Charizanis, K., Lee, K.-Y., Suzuki, Y., Kimura, T., Matsuura, T., Cisneros, B., Swanson, M.S., Trovero, F., Buisson, B., Bizot, J.-C., Hamon, M., Humez, S., Bassez, G., Metzger, F., Buée, L., Munnich, A., Sergeant, N., Gourdon, G., Gomes-Pereira, M., 2013. Myotonic dystrophy CTG expansion affects synaptic vesicle proteins, neurotransmission and mouse behaviour. Brain 136, 957-70. https://doi.org/10.1093/brain/aws367

Hunsaker, M.R., Kesner, R.P., 2008. Evaluating the differential roles of the dorsal dentate gyrus, dorsal $\mathrm{CA} 3$, and dorsal CA1 during a temporal ordering for spatial locations task. Hippocampus 18, 955-64. https://doi.org/10.1002/hipo.20455

Itoh, K., Mitani, M., Kawamoto, K., Futamura, N., Funakawa, I., Jinnai, K., Fushiki, S., 2010. Neuropathology does not Correlate with Regional Differences in the Extent of Expansion of CTG Repeats in the Brain with Myotonic Dystrophy Type 1. Acta Histochem. Cytochem. 43, 149-56. https://doi.org/10.1267/ahc.10019

Jacobs, B.L., Van Praag, H., Gage, F.H., 2000. Adult brain neurogenesis and psychiatry: A novel theory of depression. Mol. Psychiatry. https://doi.org/10.1038/sj.mp.4000712 
Kamal, S., 2013. Modulating Role of Mirtazapine on Concentrations of both Glutamate and GABA in Nucleus Accumbens of Chronic Mild Stressed Albino Rats. J. Neurol. Disord. 01. https://doi.org/10.4172/2329-6895.1000110

Kamińska, K., Noworyta-Sokołowska, K., Górska, A., Rzemieniec, J., Wnuk, A., Wojtas, A., Kreiner, G., Kajta, M., Gołembiowska, K., 2018. The Effects of Exposure to Mephedrone During Adolescence on Brain Neurotransmission and Neurotoxicity in Adult Rats. Neurotox. Res. 34, 525-537. https://doi.org/10.1007/s12640-018-9908-0

Kaser, M., Zaman, R., Sahakian, B.J., 2017. Cognition as a treatment target in depression. Psychol. Med. 47, 987-989. https://doi.org/10.1017/S0033291716003123

Kesner, R.P., Rogers, J., 2004. An analysis of independence and interactions of brain substrates that subserve multiple attributes, memory systems, and underlying processes, in: Neurobiology of Learning and Memory. https://doi.org/10.1016/j.nlm.2004.05.007

Kokras, N., Antoniou, K., Polissidis, A., Papadopoulou-Daifoti, Z., 2009. Antidepressants induce regionally discrete, sex-dependent changes in brain's glutamate content. Neurosci. Lett. 464, 98-102. https://doi.org/10.1016/j.neulet.2009.08.011

Le François, B., Czesak, M., Steubl, D., Albert, P.R., 2008. Transcriptional regulation at a HTR1A polymorphism associated with mental illness. Neuropharmacology 55, 977-85. https://doi.org/10.1016/j.neuropharm.2008.06.046

Luján, M.Á., Castro-Zavala, A., Alegre-Zurano, L., Valverde, O., 2018. Repeated Cannabidiol treatment reduces cocaine intake and modulates neural proliferation and CB1R expression in the mouse hippocampus. Neuropharmacology 143, 163-175. https://doi.org/10.1016/j.neuropharm.2018.09.043

Malberg, J.E., Eisch, A.J., Nestler, E.J., Duman, R.S., 2000. Chronic antidepressant treatment increases neurogenesis in adult rat hippocampus. J. Neurosci. 20, 9104-10.

Miller, J.W., Urbinati, C.R., Teng-Umnuay, P., Stenberg, M.G., Byrne, B.J., Thornton, C.A., Swanson, M.S., 2000. Recruitment of human muscleblind proteins to (CUG)(n) expansions associated with myotonic dystrophy. EMBO J. 19, 4439-48. https://doi.org/10.1093/emboj/19.17.4439

Minnerop, M., Gliem, C., Kornblum, C., 2018. Current Progress in CNS Imaging of Myotonic Dystrophy. Front. Neurol. 9, 646. https://doi.org/10.3389/fneur.2018.00646 
Mizukami, K., Sasaki, M., Baba, A., Suzuki, T., Shiraishi, H., 1999. An autopsy case of myotonic dystrophy with mental disorders and various neuropathologic features. Psychiatry Clin. Neurosci. 53, 51-5. https://doi.org/10.1046/j.1440-1819.1999.00470.x

Modoni, A., Silvestri, G., Vita, M.G., Quaranta, D., Tonali, P.A., Marra, C., 2008. Cognitive impairment in myotonic dystrophy type 1 (DM1): a longitudinal follow-up study. J. Neurol. 255, 1737-42. https://doi.org/10.1007/s00415-008-0017-5

Muguruza, C., Rodríguez, F., Rozas, I., Meana, J.J., Urigüen, L., Callado, L.F., 2013. Antidepressantlike properties of three new a2-adrenoceptor antagonists. Neuropharmacology. https://doi.org/10.1016/j.neuropharm.2012.09.003

Müller, N., Schwarz, M.J., 2007. Immunologische Aspekte bei depressiven Störungen. Nervenarzt 78, 1261-1273. https://doi.org/10.1007/s00115-007-2311-3

Nätterlund, B., Ahlström, G., 2001. Activities of daily living and quality of life in persons with muscular dystrophy. J. Rehabil. Med. 33, 206-11. https://doi.org/10.1080/165019701750419590

Olesti, E., De Toma, I., Ramaekers, J.G., Brunt, T.M., Carbó, M., Fernández-Avilés, C., Robledo, P., Farré, M., Dierssen, M., Pozo, Ó.J., de la Torre, R., 2019. Metabolomics predicts the pharmacological profile of new psychoactive substances. J. Psychopharmacol. https://doi.org/10.1177/0269881118812103

Olesti, E., Rodríguez-Morató, J., Gomez-Gomez, A., Ramaekers, J.G., de la Torre, R., Pozo, O.J., 2019. Quantification of endogenous neurotransmitters and related compounds by liquid chromatography coupled to tandem mass spectrometry. Talanta 192, 93-102. https://doi.org/10.1016/j.talanta.2018.09.034

Oliveira, T. de Q., Sousa, C.N.S. de, Vasconcelos, G.S., de Sousa, L.C., de Oliveira, A.A., Patrocínio, C.F.V., Medeiros, I. da S., Honório Júnior, J.E.R., Maes, M., Macedo, D., Vasconcelos, S.M.M., 2017. Brain antioxidant effect of mirtazapine and reversal of sedation by its combination with alpha-lipoic acid in a model of depression induced by corticosterone. J. Affect. Disord. https://doi.org/10.1016/j.jad.2017.05.022

Ono, S., Takahashi, K., Jinnai, K., Kanda, F., Fukuoka, Y., Kurisaki, H., Mitake, S., Inagaki, T., Yamano, T., Nagao, K., 1998a. Loss of serotonin-containing neurons in the raphe of patients with myotonic dystrophy: A quantitative immunohistochemical study and relation to hypersomnia. Neurology 50, 535-538. https://doi.org/10.1212/WNL.50.2.535

Ono, S., Takahashi, K., Jinnai, K., Kanda, F., Fukuoka, Y., Kurisaki, H., Mitake, S., Inagaki, T., Yamano, T., Shimizu, N., Nagao, K., 1998b. Loss of catecholaminergic neurons in the 
medullary reticular formation in myotonic dystrophy. Neurology 51, 1121-1124. https://doi.org/10.1212/WNL.51.4.1121

Papakostas, G.I., Culpepper, L., 2015. Understanding and managing Cognition in the Depressed Patient. J. Clin. Psychiatry 76, 418-25. https://doi.org/10.4088/JCP.13086ah1c

Porsolt, R.D., Bertin, A., Jalfre, M., 1977. Behavioral despair in mice: a primary screening test for antidepressants. Arch. Int. Pharmacodyn. Ther. 229, 327-36.

Ramon-Duaso, C., Gener, T., Consegal, M., Fernández-Avilés, C., Gallego, J.J., Castarlenas, L., Swanson, M.S., de la Torre, R., Maldonado, R., Puig, M.V., Robledo, P., 2019. Methylphenidate Attenuates the Cognitive and Mood Alterations Observed in Mbnl2 Knockout Mice and Reduces Microglia Overexpression. Cereb. cortex 29, 2978-2997. https://doi.org/10.1093/cercor/bhy164

Ribeiro, J.A., Sebastião, A.M., de Mendonça, A., 2002. Adenosine receptors in the nervous system: pathophysiological implications. Prog. Neurobiol. 68, 377-92.

Richardson, L., Adams, S., 2018. Cognitive Deficits in Patients With Depression. J. Nurse Pract. 14, 437-443.e3. https://doi.org/10.1016/j.nurpra.2018.03.006

Rocha, S.M., Saraiva, T., Cristóvão, A.C., Ferreira, R., Santos, T., Esteves, M., Saraiva, C., Je, G., Cortes, L., Valero, J., Alves, G., Klibanov, A., Kim, Y.S., Bernardino, L., 2016. Histamine induces microglia activation and dopaminergic neuronal toxicity via $\mathrm{H} 1$ receptor activation. J. Neuroinflammation 13. https://doi.org/10.1186/s12974-016-0600-0

Rogóż, Z., 2013. Effect of combined treatment with mirtazapine and risperidone on the MK-801induced changes in the object recognition test in mice. Pharmacol. Rep. 65, 1401-6.

Romeo, V., Pegoraro, E., Squarzanti, F., Sorarù, G., Ferrati, C., Ermani, M., Zucchetta, P., Chierichetti, F., Angelini, C., 2010. Retrospective study on PET-SPECT imaging in a large cohort of myotonic dystrophy type 1 patients. Neurol. Sci. 31, 757-63. https://doi.org/10.1007/s10072-010-0406-2

Russo, M., Mahon, K., Burdick, K.E., 2015. Measuring cognitive function in MDD: emerging assessment tools. Depress. Anxiety 32, 262-9. https://doi.org/10.1002/da.22297

Sampath, D., Sathyanesan, M., Newton, S.S., 2017. Cognitive dysfunction in major depression and Alzheimer's disease is associated with hippocampal-prefrontal cortex dysconnectivity. Neuropsychiatr. Dis. Treat. https://doi.org/10.2147/NDT.S136122 
Sansone, V., Gandossini, S., Cotelli, M., Calabria, M., Zanetti, O., Meola, G., 2007. Cognitive impairment in adult myotonic dystrophies: a longitudinal study. Neurol. Sci. 28, 9-15. https://doi.org/10.1007/s10072-007-0742-z

Santarelli L, Saxe M, Gross C, Surget A, Battaglia F, Dulawa S, et al. Requirement of hippocampal neurogenesis for the behavioral effects of antidepressants. Science. 2003 Aug 8;301(5634):805-9.

Saravia, R., Ten-Blanco, M., Grande, M.T., Maldonado, R., Berrendero, F., 2019. Anti-inflammatory agents for smoking cessation? Focus on cognitive deficits associated with nicotine withdrawal in male mice. Brain. Behav. Immun. 75, 228-239. https://doi.org/10.1016/j.bbi.2018.11.003

Satoh, J.-I., Kino, Y., Yanaizu, M., Tosaki, Y., Sakai, K., Ishida, T., Saito, Y., 2016. Expression of gp91phox and p22phox, catalytic subunits of NADPH oxidase, on microglia in Nasu-Hakola disease brains. Intractable rare Dis. Res. 5, 275-279. https://doi.org/10.5582/irdr.2016.01086

Stenberg, J.-H., Terevnikov, V., Joffe, M., Tiihonen, J., Chukhin, E., Burkin, M., Joffe, G., 2013. Predictors and mediators of add-on mirtazapine-induced cognitive enhancement in schizophrenia--a path model investigation. Neuropharmacology 64, 248-53. https://doi.org/10.1016/j.neuropharm.2012.06.028

Strobel, A., Gutknecht, L., Rothe, C., Reif, A., Mössner, R., Zeng, Y., Brocke, B., Lesch, K.-P., 2003. Allelic variation in $5-\mathrm{HT} 1 \mathrm{~A}$ receptor expression is associated with anxiety- and depressionrelated personality traits. J. Neural Transm. 110, 1445-53. https://doi.org/10.1007/s00702-0030072-0

Sutcigil, L., Oktenli, C., Musabak, U., Bozkurt, A., Cansever, A., Uzun, O., Sanisoglu, S.Y., Yesilova, Z., Ozmenler, N., Ozsahin, A., Sengul, A., 2007. Pro- and anti-inflammatory cytokine balance in major depression: effect of sertraline therapy. Clin. Dev. Immunol. 2007, 76396. https://doi.org/10.1155/2007/76396

Takado, Y., Terajima, K., Ohkubo, M., Okamoto, K., Shimohata, T., Nishizawa, M., Igarashi, H., Nakada, T., 2015. Diffuse brain abnormalities in myotonic dystrophy type 1 detected by $3.0 \mathrm{~T}$ proton magnetic resonance spectroscopy. Eur. Neurol. 73, 247-56. https://doi.org/10.1159/000371575

Tettamanti, M., Armstrong, J.D., Endo, K., Yang, M.Y., Furukubo-Tokunaga, K., Kaiser, K., Reichert, H., 1997. Early development of the Drosophila mushroom bodies, brain centres for associative learning and memory. Dev. Genes Evol. 207, 242-252. https://doi.org/10.1007/s004270050112 
Tulner, D.M., Smith, O.R.F., Schins, A., de Jonge, P., Quere, M., Delanghe, J.R., Crijns, H.J., den Boer, J.A., Korf, J., Honig, A., 2011. Antidepressive effect of mirtazapine in post-myocardial infarction depression is associated with soluble TNF-R1 increase: data from the MIND-IT. Neuropsychobiology 63, 169-76. https://doi.org/10.1159/000321624

Udd, B., Krahe, R., 2012. The myotonic dystrophies: molecular, clinical, and therapeutic challenges. Lancet. Neurol. 11, 891-905. https://doi.org/10.1016/S1474-4422(12)70204-1

Vielhaber, S., Jakubiczka, S., Gaul, C., Schoenfeld, M.A., Debska-Vielhaber, G., Zierz, S., Heinze, H.-J., Niessen, H.G., Kaufmann, J., 2006. Brain 1H magnetic resonance spectroscopic differences in myotonic dystrophy type 2 and type 1. Muscle Nerve 34, 145-52. https://doi.org/10.1002/mus.20565

Wang, P.-Y., Lin, Y.-M., Wang, L.-H., Kuo, T.-Y., Cheng, S.-J., Wang, G.-S., 2017. Reduced cytoplasmic MBNL1 is an early event in a brain-specific mouse model of myotonic dystrophy. Hum. Mol. Genet. 26, 2247-2257. https://doi.org/10.1093/hmg/ddx115

Winblad, S., Samuelsson, L., Lindberg, C., Meola, G., 2016. Cognition in myotonic dystrophy type 1: a 5-year follow-up study. Eur. J. Neurol. 23, 1471-1476. https://doi.org/10.1111/ene.13062

Wojtowicz, J.M., Kee, N., 2006. BrdU assay for neurogenesis in rodents. Nat. Protoc. 1, 1399-405. https://doi.org/10.1038/nprot.2006.224

Wolff, M., Costet, P., Gross, C., Hen, R., Segu, L., Buhot, M.-C., 2004. Age-dependent effects of serotonin-1A receptor gene deletion in spatial learning abilities in mice. Brain Res. Mol. Brain Res. 130, 39-48. https://doi.org/10.1016/j.molbrainres.2004.07.012 


\section{FIGURE LEGENDS}

Figure 1. Transgenic Drosophila and mouse models used in the study (a-d), mirtazapine doseresponse locomotor study (e), and sequence of behavioral and biochemical experiments following mirtazapine treatment (f). (a) Representative images of control Drosophila males expressing no repeats in the mushroom bodies (MB) and emerging from pupae (normal fly). DM1 females unable to completely emerge from the pupal stage (minus compound), and DM1 females rescued by the oral administration of defined drugs (plus compound). (b) Confocal image of the MB structure marked by GFP reporter under the control of MB-Gal4 driver (green) and a graphical representation of the left lobe of the MBs. (c) 96-well trays were used for the screening of 1200 compounds. (d) Generation of Mbn/2NEX-cKO mice. Two sequential crosses were made: First we outcrossed (shaded in blue) a brainspecific Cre transgene (NEX-Cre+ ${ }^{+-}$) mouse strain with homozygous Mbn/2 loxP-flanked mice $\left(\mathrm{Mbn} / 2^{\mathrm{ff} / \mathrm{f}}\right)$. In the $\mathrm{F} 1$ generation, around the $50 \%$ of the offspring was hemizygous for the Cre transgene and for the loxP-flanked allele $\left(\mathrm{Cre}^{++-;} \mathrm{Mbn} / 2^{2 /++}\right)$. These were backcrossed (shaded in green) with the homozygous Mbn/2 LoxP-flanked mice (Mbn/2fffli). In the N1 generation, approximately $25 \%$ of the progeny was hemizygous for the Cre transgene and homozygous for the loxP-flanked allele (Cre+-; Mbn/2nffr), resulting in our conditional knockout mice (Mbn/2NEX-ckO), and around $25 \%$ of mice were homozygous for the loxP-flanked allele, but non-carriers of the Cre transgene (Cre--; Mbn/2ff/f) , resulting in our control wild-type group. (e) Locomotor dose-response performed in male WT mice treated daily for 5 consecutive days with vehicle (VEH) or mirtazapine (1, 3,10 and $30 \mathrm{mg} / \mathrm{kg}$ ). Horizontal locomotion in $1 \mathrm{~h}$ was significantly decreased in mice treated with the dose of $30 \mathrm{mg} / \mathrm{kg}$ with respect to vehicle administration ( ${ }^{*} \mathrm{p}<0.05$ ). (f) Timeline of behavioral and biochemical procedures following chronic treatment with mirtazapine. 
Figure 2. In vivo drug screening using the MB-Gal4 Drosophila line (a-d), and validation of the conditional knock-out strategy of Mbn/2NEX-cKO mice (e-f). (a) Compounds showing anti-DM1 effect in the Drosophila model: the table indicates the number of hits from each therapeutic group. (b) Pharmacological studies with mirtazapine (MRZ) at different concentrations: the number of adults (male and female) which emerged from pupae with standard nutritive media supplemented with DMSO (control) or with the indicated concentrations of MRZ at $28^{\circ} \mathrm{C}$; in the control DMSO treatment, a small percentage of females were able to emerge $(n=15)$, whereas following MRZ (1 and $10 \mu M)$ an increase in female offspring was detected ( $n=20$ and $n=14$, respectively). (c) At $29^{\circ} \mathrm{C}$, no female pupae hatched in the non-treated group, while MRZ $(0.1$ and $1 \mu \mathrm{M})$ rescued at least 1 adult female. (d) The atypical antidepressant MRZ, with a multimodal activity, had anti-DM1 activity, while closely related compounds with different pharmacological profiles did not show a significant rescue. Hit compounds were required to score at least 5 males in each of the 3 replicates to discard toxicity issues. ${ }^{*} p<0.05,{ }^{* *} p<0.01$ (Fisher's Exact test). (e) Western blot analysis of MBNL2 protein levels in the mPFC, HPC, striatum and cerebellum in WT and Mbn/2NEX-cKO. The panels on the right represent the bands of relative intensity of MBNL2 (upper) and GAPDH (lower) used as a loading control. (f) Immunoreactivity of MBNL2 in the PFC and HPC of WT and Mbnl2NEX-cKO mice. The panels on the right show representative images of MBNL2 intensity (green). Scale bar=500 $\mu \mathrm{m}$. Images were taken at $x 4$ magnification. Values are the mean $+\mathrm{SEM} .{ }^{* * *} \mathrm{p}<0.001$ vs. WT group (one-way ANOVA).

Figure 3. Behavioral assessment of locomotor activity, long-term recognition memory and depression-like state in WT and Mbn/2NEX-cKO mice at 3 and 8 months of age. No significant alterations were observed between groups in (a) horizontal locomotion or (b) number of rearings. (c) In the novel object recognition test, long-term memory was impaired in the Mbn/2NEX-ckO mice, 
showing lower rates of discrimination index at 3 and 8 months of age compared to WT mice. (d) In the forced swim test, immobility was increased in Mbn/2NEX-cKO mice at 3 and 8 months of age with respect to WT mice. Values are the mean + SEM. ${ }^{* * \star} p<0.001$ vs. WT group (two-way ANOVA followed by Bonferroni's post-hoc analysis). $\$ \$ \$<0.001$ (main effect of genotype).

Figure 4. Effects of chronic treatment with vehicle (VEH) and mirtazapine (MRZ) on locomotor activity, long-term recognition memory and depression-like behavior in Mbn/2NEX-cKO and WT mice. (a) Horizontal locomotion and (b) number of rearings evaluated during 30 min were not significantly different between groups. (c) In the novel object recognition test, long-term memory was significantly decreased in Mbn/2NEX-ckO mice treated with VEH, and both doses of MRZ reversed this cognitive impairment. (d) In the forced swim test, immobility time was significantly increased in Mbnl2NEX-cKO mice treated with VEH, and both doses of MRZ attenuated this depressive-like state. Values are the mean + SEM. ${ }^{* * *} p<0.001$ vs. WT group (genotype effect). \#\# $p<0.001$ vs. VEH of same genotype (treatment effect) (two-way ANOVA followed by Bonferroni's post-hoc analysis).

Figure 5. Effects of chronic treatment with vehicle (VEH) and mirtazapine (MRZ) on the number of microgila (Iba1) in the hippocampus of WT and Mbn/2NEX-cKO mice. (a) In the dentate gyrus, Iba1 immunoreactivity was enhanced in Mbn/2NEX-cKO mice treated with VEH, and both doses of MRZ attenuated this overexpression. In the hippocampus, the transcriptional levels of $(b)$ interleukin 1 beta (IL-1 $\beta$ ) were enhanced in Mbn/2NEX-cKO treated with VEH, and both doses of MRZ reversed this cytokine production, whereas no differences were observed between groups in the gene expression of (c) transforming growth factor (TGF- $\beta$ ). The Y-axis shows the mRNA expression as a fold change compared with the control group (WT VEH). (d) Representative images of Iba1 positive cells (red) and DAPI counterstaining (blue) in the DG region of WT and Mbn/2NEX-ckO mice. Scale bar $=200 \mu \mathrm{m}$. 
Values are the mean + SEM. ${ }^{*} p<0.05,{ }^{* * *} p<0.001$ vs. WT group (genotype effect). \#\# $p<0.01, \# \#$ $p<0.001$ vs. VEH of same genotype (treatment effect) (two-way ANOVA followed by Bonferroni's post-hoc analysis).

Figure 6. Effects of chronic treatment with vehicle (VEH) and mirtazapine (MRZ) on the expression of mature neurons (NeuN), proliferating neurons (BrdU), and immature neurons (DCX) in the dentate gyrus of WT and Mbn/2NEX-cKO mice. (a) A significant decrease in NeuN positive cells was found in Mbn/2NEX-cKO treated with VEH, and MRZ at $10 \mathrm{mg} / \mathrm{kg}$ reversed this neuronal loss. (b) Representative images of NeuN positive cells (green). Scale bar $=200 \mu \mathrm{m}$. (c) MRZ increased the number of BrdU positive cells in WT and Mbn/2NEX-ckO mice. (d) Representative images of BrdU positive cells (green dots) Scale bar $=400 \mu \mathrm{m}$. (e) DCX expression was reduced in Mbnl2 ${ }^{\text {NEX-cKO }}$ treated with VEH, and MRZ increased the expression of this marker in WT and Mbnl2NEX-cKO mice. (f) Representative images of DCX positive cells (red marker). Scale bar $=400 \mu \mathrm{m}$. Values are the mean + SEM. ${ }^{* *} p<0.01,{ }^{* * *} p<0.001$ vs. WT group (genotype effect). $\# p<0.05, \# \#<0.01, \# \# p<0.001$ vs. VEH of same genotype (treatment effect). +++ (main effect of treatment). (two-way ANOVA followed by Bonferroni's post-hoc analysis).

Figure 7. Effects of chronic treatment with vehicle (VEH) and mirtazapine (MRZ) on the transcriptional levels of neurotransmitter receptors in WT and Mbn/2 genotype between WT and Mbn/2NEX-ckO mice was found in the gene expression of (a) $5-\mathrm{HT}_{2 \mathrm{~A}}$ and (b) 5-HT $2 \mathrm{C}$ serotonin receptors. (c) $5-\mathrm{HT}_{1 \mathrm{~A}}$ receptor expression was significantly reduced in the Mbn/2 ${ }^{\mathrm{NEX}}$ ckO mice treated with VEH, and MRZ at $10 \mathrm{mg} / \mathrm{kg}$ increased its expression. (d) Histaminergic $\mathrm{H}_{1}$ receptor expression was increased in the Mbn/2NEX-cKO mice treated with VEH, and both doses of MRZ attenuated this expression. No significant differences between groups were observed in the transcriptional levels of $(e) a_{2 A}$ or $(f) 5-H_{3}$ receptors. The $Y$-axis shows the mRNA expression as a 
fold change compared with the control group (WT VEH). Values are the mean + SEM. ${ }^{*} p<0.05$, ${ }^{* * *} p<0.001$ vs. WT group (genotype effect). \#p<0.05, \#p <0.01 vs. VEH of same genotype (treatment effect). \$ (main effect of genotype). (two-way ANOVA followed by Bonferroni's post-hoc analysis).

Figure 8. Effects of chronic treatment with vehicle (VEH) and mirtazapine (MRZ) on brain metabolites in WT and Mbnl2 ${ }^{\mathrm{NEX}-\mathrm{ckO}}$ mice. The production of 5-HT (5-HT/Trp), NA (NA/Tyr), GABA (GABA/GI), glutamate $(G / u / G \mid n)$ and the levels of adenosine were quantified in the medial prefrontal cortex (mPFC) (a-e), and in the hippocampus (HPC) (f-j). In the mPFC, 5-HT/Trp (a) was significantly reduced in WT mice treated with MRZ at $10 \mathrm{mg} / \mathrm{kg}$, and NA/Tyr (b) was significantly reduced in Mbn/2NEX-ckO mice treated with VEH, and WT mice treated with MRZ at $10 \mathrm{mg} / \mathrm{kg}$. In the HPC, 5$\mathrm{HT} / \mathrm{Trp}$ (f) was significantly reduced in Mbn/2NEX-cKO mice treated with VEH, and MRZ at $10 \mathrm{mg} / \mathrm{kg}$ significantly decreased its production in WT mice. (g) MRZ at $10 \mathrm{mg} / \mathrm{kg}$ significantly reduced NA/Tyr in WT mice, and increased this ratio in Mbn/2NEX-cKO mice. (h) GABA/Glu was significantly increased in Mbn/2NEX-cKO mice by MRZ at $10 \mathrm{mg} / \mathrm{kg}$. (j) adenosine levels were reduced in Mbn/2NEX-ckO mice treated with VEH, and MRZ at $10 \mathrm{mg} / \mathrm{kg}$ reversed this effect. Data is expressed as metabolic ratios (area of the analyte/area of internal standard). Values are the mean + SEM. ${ }^{*} p<0.05,{ }^{* * *} p<0.001$ vs. WT group (genotype effect). \#p<0.05, \#p< $<0.01$ vs. VEH of same genotype (treatment effect). $\$$ (main effect of genotype). (two-way ANOVA followed by Bonferroni's post-hoc analysis). 